\title{
AS MUDANÇAS NO PERCURSO DO OLHAR (GAZE) SÃO INDICATIVAS DA SEGMENTAÇÃO TEXTUAL DO TRADUTOR? ${ }^{1}$
}

\author{
ARE GAZE SHIFTS A KEY TO A TRANSLATOR'S TEXT \\ SEGMENTATION?
}

\author{
Arnt Lykke JAKOBSEN ${ }^{2}$ \\ Tradução de: Laurieny VILELA e Cecília Franco MORAIS ${ }^{3}$
}

\begin{abstract}
Resumo: O registro dos acionamentos de teclas e mouse (key logging) demonstra que a produção textual do tradutor pode ser decomposta em unidades delimitadas por fronteiras de pausas (DRAGSTED, 2004, 2005, 2010). Em contrapartida, pesquisas sobre leitura não identificaram fronteiras análogas, visto que as únicas interrupções na atenção visual do leitor consistem, na maioria das vezes, somente em piscadelas de olhos. No entanto, em um experimento envolvendo o rastreamento dos movimentos do olhar de um tradutor em uma tela que apresentava o texto-fonte e o texto-alvo (em processo de produção), os dados do olhar (gaze) mostraram mudanças na atenção visual do tradutor entre os dois textos. Será que tais mudanças podem ser vistas como um indicador de unidades de processamento de conteúdo? Será que tais mudanças nos fornecem informações mais precisas sobre a segmentação ou, pelo menos, são mais informativas que os intervalos nos acionamentos de teclas e mouse? Usando, a título de ilustração, um registro com baixa qualidade de calibração de apenas uma tradução de uma única sentença (extraída de uma tarefa maior), este trabalho tem por objetivo (i) explorar a possibilidade de se identificar segmentos - entendidos como unidades de processamento - com base nas mudanças do percurso do olhar e (ii) investigar o que motiva tais mudanças. Esta pesquisa também busca mostrar em que medida a nossa interpretação das representações do olhar (gaze), ainda representações não ideais, dependem de uma teoria da leitura.
\end{abstract}

Palavras-chave: Pesquisa do processo tradutório. Segmentação. Mudanças na atenção. Unidades de atenção. Unidades de processamento. Unidades de tradução. Rastreamento ocular.

\section{Introdução: segmentação baseada no registro de acionamentos de teclas e mouse}

Quando se observa como uma tradução normalmente é digitada, talvez uma das características mais notáveis é que se trata de um processo irregular, com curtos períodos de digitação alternados com pausas. Essa característica é ainda mais marcante no processo de tradutores inexperientes. Em se tratando de tradutores mais experientes, o processo de

\footnotetext{
${ }^{1}$ Agradecemos ao autor a gentileza de ceder os direitos para a publicação desta versão traduzida. Referência do artigo original: JAKOBSEN, Arnt Lykke. Are gaze shifts a key to a translator's text segmentation? Poznan Studies in Contemporary Linguistics, v. 52, n. 2, p. 149-174, jun. 2016. DOI: https://doi.org/10.1515/psicl-20160015.

${ }^{2}$ Copenhagen Business School

${ }^{3}$ Laurieny Vilela: Tradutora de inglês e espanhol. Possui Bacharelado em Tradução pela Universidade Federal de Uberlândia (2014). Mestranda em Estudos da Tradução pela Universidade de Brasília. Email: laurienyy@gmail.com. Cecília Franco Morais: Professora e tradutora de inglês. Possui Licenciatura em Letras (2008) e cursa Bacharelado em Tradução (desde 2014) pela Universidade Federal de Uberlândia. Atua como professora de inglês em escolas da Prefeitura Municipal de Uberlândia. E-mail: cecilia.fm.04@gmail.com. Tradução supervisionada pelo Prof. Dr. Igor Antonio Lourenço da Silva.
} 
digitação pode ser mais consistente e mais rítmico, mas, ainda assim, costuma compreender sequências de digitação alternadas com pausas durante as quais não há uso do teclado. Poucos tradutores são capazes de produzir uma tradução escrita sem manifestar algum tipo de alternância ou segmentação.

Há anos as pausas têm sido investigadas como indicadores de processamento (e.g., GOLDMAN-EISLER， 1972; BUTTERWORTH， 1980; BADDELEY， 1986; SCHILPEROORD, 1996; JAKOBSEN, 20034; IMMONEN, MÄKISALO, 2010). Elas têm sido vistas como indicadores importantes de processos cognitivos. Na maioria desses estudos, são estudadas como uma característica da comunicação oral. Goldman-Eisler (1972, p. 103), ao estudar as pausas para investigar a "realidade psicológica" de estruturas sintáticas e ao contrastar as pausas em falas espontâneas com aquelas observadas em textos lidos em voz alta, observou diferenças substantivas na distribuição das pausas. Schilperoord (1996), ao estudar documentos jurídicos sendo ditados por advogados, encontrou uma clara correlação entre a duração das pausas e as unidades linguísticas em diferentes níveis. Immonent e Mäkisalo (2010), ao compararem a produção textual monolíngue (de falantes nativos de finlandês escrevendo um texto nessa língua) com a produção textual bilíngue para a L1 (de falantes nativos de finlandês traduzindo do inglês para o finlandês), identificaram que considerando os intervalos entre os acionamentos de teclas desde aqueles encontrados entre sílabas até aqueles no nível na oração (mas não acima desse nível) - as pausas eram mais longas na produção dos textos bilíngues do que na produção dos textos monolíngues, o que indica que a produção bilíngue envolveria um maior esforço cognitivo em todos os níveis em questão. Contudo, nos níveis da sentença e do parágrafo, as pausas entre as unidades eram mais longas na produção monolíngue do que na bilíngue, o que indica que o esforço de planejamento avançado demandado do nível da sentença para cima - no "nível do macroplanejamento", nos termos de Butterworth (1980, p. 159) - seria maior na produção de textos monolíngues do que na produção bilíngue. Em outras palavras, o esforço extra demandado na produção bilíngue (em comparação com a produção monolíngue) é contrabalanceado pelo esforço do macroplanejamento (nos níveis mais altos), que é demandado na produção monolíngue, mas não no processo de tradução. Assim, o registro de acionamentos de teclas e mouse evidencia que fenômenos de hesitação, similares àqueles encontrados na fala, podem ser observados na digitação de um texto-alvo pelo tradutor. A pausa, portanto, não é somente um forte indicador da natureza rítmica do processamento

\footnotetext{
${ }^{4}$ Jakobsen (2003) encontra-se traduzido neste volume.
} 
linguístico, mas também fornece evidências da quantidade de esforço cognitivo envidado em qualquer ponto do processo.

Segmentos baseados em acionamentos de teclas e mouse são frequentemente identificados por meio da aplicação de um critério temporal arbitrário de delimitação do "valor de pausa" para a definição das fronteiras desses segmentos, em geral entre 1 e 5 segundos (para uma discussão sobre o tema, cf. DRAGSTED, 2004, p. 104-105; ALVES; VALE, 2009, p. 255). Assume-se, nesses casos, que existe uma correlação entre a duração da pausa e o esforço de processamento, de modo que pausas mais longas indicam maior esforço mental. Dentro dos segmentos, é possível identificar subsegmentos, novamente com base na duração dos intervalos entre os acionamentos de teclas e mouse. Todavia, a segmentação também pode ser estudada a partir de outras fontes de evidência, como os movimentos oculares, conforme será mostrado a seguir.

Considerando os acionamentos de teclas, seria possível chegar à seguinte representação da digitação da sentença, em alemão, "Gestern wurde er nach langem Gerichtsverfahren des vierfachen Mordes schuldig gesprochen.", produzida por um tradutor ${ }^{5}$ a partir do texto-fonte, em inglês, "Yesterday, he was found guilty of four counts of murder following a long trial." ["Ontem ele foi considerado culpado em quatro acusações de homicídio ao cabo de um longo julgamento.”], extraído de uma curta notícia de jornal:

Figura 1 - Representação dos acionamentos de teclas com a supressão de pausas inferiores a $250 \mathrm{~ms}$ (à exceção de um intervalo de tempo ligeiramente inferior no final)

$[\cdot 01.529]$ Gestern $\bullet$ wurde $\bullet[\cdot 00.874]$ er $\bullet[\cdot 00.944]$ des $\bullet$ vierfachen $\bullet$ Morde $[\cdot 01.560]<4<[\bullet 00.905]$ in $\bullet$ Folge $\bullet$ e ines $\cdot[\cdot 00.608] \mathrm{la}[\cdot 04.493]$ ४ nach $\cdot[\cdot 00.359]$ lange $[\cdot 00.843] \mathrm{m} \cdot \mathrm{F}[\cdot 00.359][$ Shift+Back] Ver[ $[\cdot 00.375]$

$[$ Shift+Back]Gerichtsverfahren $\bullet[\cdot 00.983]$ des $\bullet$ vierfachen $\bullet$ Mordes $\bullet[\bullet 00.765]$ schg $[\bullet 00.702]<u[\cdot 00.234]$ ldig $\cdot$ gesproch en. $\cdot[\cdot 04.134]$

Nessa representação, foram considerados somente os intervalos com duração igual ou superior a $250 \mathrm{~ms}$ entre os acionamentos de teclas (com uma única exceção). Um efeito dessa escolha é que se pode constatar que pausas iguais ou superiores a $250 \mathrm{~ms}$ tendem a ocorrer entre palavras ou sintagmas completos, havendo ocorrências no meio de palavras somente em casos de erro de digitação ou interrupção da digitação em razão de o tradutor ter

\footnotetext{
${ }^{5}$ Nenhuma informação sobre o participante P01 (U88) está inclusa nos metadados do TPR-DB, banco de dados do processo tradutório (cf. artigo de Michae lCarl, Moritz Schaeffer e Srinivas Bangalore, neste volume), sendo a identidade da pessoa desconhecida para o autor. A atribuição do gênero masculino é arbitrária. O leitor interessado na dinâmica do processo pode baixar o banco de dados TPR-DB e o software Translog-II, ambos de livre acesso, por meio do sítio eletrônico disponível em: $<$ https://sites.google.com/site/centretranslationinnovation/>.
} 
repentinamente cogitado uma solução diferente. A tradução de "Yesterday, he was found guilty of four counts of murder", em um primeiro momento, ocorreu sem problemas, incluindo para o rearranjo, necessário na tradução, de "he was" ["ele foi"] para "wurde er" ["foi ele"]. A falta do " $s$ " no final de "Morde", seguida de uma longa pausa e de vários acionamentos da tecla de retrocesso (backspace), indica que o tradutor pensou em outra opção. A nova tradução (mais uma vez) envolveu o rearranjo da estrutura da informação, havendo o reposicionamento do sintagma adverbial final "following a long trial" para um ponto anterior na sentença. O tradutor parece não ter levado em consideração esse sintagma adverbial ao digitar o sintagma anterior. Então, quando estava para digitar "langen", o tradutor interrompeu a digitação (logo depois de digitar "la"), visto que teve uma nova ideia para a tradução de "following", ideia essa que ensejava uma reinterpretação da palavra. A relação causal ou consecutiva sugerida por "in Folge" ["como resultado de"] foi descartada e substituída por uma relação puramente temporal ("nach", ou seja, "após"). A realização dessa mudança, que envolveu pensar nos rearranjos necessários à construção da sentença, levou cerca de 4,5 s e ensejou o maior intervalo de digitação encontrado no processo de tradução dessa sentença. Por fim, o tradutor procedeu a uma especificação do termo genérico "Verfahren" ["processo(s)"], que foi substituído por "Gerichtsverfahren" ["processo judicial"], e digitou o restante da sentença sem maiores problemas, havendo apenas um erro de digitação em "schg" [em "schuldig"], que causou um pequeno atraso na produção.

A forma como se escolhe dividir em segmentos uma representação de acionamentos de teclas e mouse dependerá do nível de refinamento da análise. Na literatura, os critérios para delimitação das fronteiras dos segmentos normalmente são fixados entre as durações de 1 e 5 segundos. No caso em análise, o tradutor digitava muito rápido, alcançando com frequência a velocidade de aproximadamente dez toques por segundo. Pelo critério de delimitação de pausas de pelo menos 1 segundo, nosso exemplo se divide somente em três segmentos, sendo que, intuitivamente, parece ser contraproducente interpretar que o último deles tenha sido processado como um único segmento ou "grupo" de informações, haja vista que se trata de um trecho extremamente longo. 
Figura 2 - Segmentação pelo critério de delimitação de pausas de pelo menos $1 \mathrm{~s}$

1. $[\cdot 01.529]$ Gestern $\bullet$ wurde $\cdot[\cdot 00.874]$ er $\cdot[\cdot 00.944]$ des $\bullet$ vierfachen $\bullet$ Morde

2. $[\cdot 01.560] \triangleleft 4<[\cdot 00.905] \mathrm{in} \cdot$ Folge $\cdot$ eines $\cdot[\cdot 00.608] \mathrm{la}$

3. $[\cdot 04.493] \varangle$ nach $\cdot[\cdot 00.359]$ lange $[\cdot 00.843] \mathrm{m} \cdot \mathrm{F}[\cdot 00.359][$ Shift+Back]Ver $[\cdot 00.375]$

[Shift+Back]Gerichtsverfahren $\cdot[\cdot 00.983]$ des $\bullet$ vierfachen $\bullet$ Mordes $\bullet[\cdot 00.765]$ schg $[\cdot 00.702]<u$ $[\cdot 00.234]$ ldig $\cdot g e s p r o c h e n$.

Ao diminuir o critério de delimitação das pausas para o mínimo de 0,9 s, obtêm-se o dobro de segmentos e, dos pontos de vista gramatical, cognitivo e intuitivo, uma visão mais atraente dos grupos de informações com os quais o tradutor deve ter trabalhado:

Figura 3. Representação dos acionamentos de teclas segmentados com base no critério de pausas de pelo menos $900 \mathrm{~ms}$

1. $[\cdot 01.529]$ Gestern $\bullet$ wurde $\cdot[\cdot 00.874]$ er

2. $[\cdot 00.944]$ des $\bullet$ vierfachen $\bullet$ Morde

3. $[\cdot 01.560]$

4. $[\cdot 00.905]$ in $\bullet$ Folge $\bullet$ eines $\cdot[\cdot 00.608]$ la

5. $[\cdot 04.493] \triangleleft$ nach $\bullet[\cdot 00.359]$ lange $[\cdot 00.843] \mathrm{m} \bullet F[\cdot 00.359][$ Shift+Back]Ver[$[\cdot 00.375]$

Gerichtsverfahren•

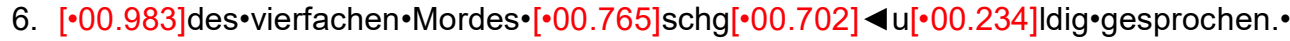

O critério de pausas de no mínimo 900 ms aumenta o número de segmentos para seis. Deles, um (o terceiro) consistiu na exclusão de um trecho que estava no lugar errado, mas seria utilizado posteriormente, e outro (o quarto) foi descartado logo em seguida (no início do quinto segmento) e substituído pela solução contendo "nach" ["após"].

Outras subdivisões são possíveis, mas é óbvio que, quanto menor a duração das pausas, mais fragmentado será o conteúdo dos segmentos por elas delimitados. Na única sentença utilizada como exemplo neste trabalho, o critério de delimitação de segmentos com base em pausas de qualquer duração de pelo menos 400 a $600 \mathrm{~ms}$ levaria aos dez segmentos seguintes, uma opção que não é, ainda, por demais fragmentada (CARL; KAY, 2011, p. 954): "Gestern wurde / er / des vierfachen Morde / 44 / in Folge eines / la / 4 nach langem Gerichtsverfahren / des vierfachen Mordes / schg / ४ ldig gesprochen”.

O critério de máxima relevância depende do foco de interesse do pesquisador e de sua habilidade em estabelecer conexões plausíveis entre um segmento escrito e uma unidade de processamento. A mente de um tradutor pode prestar atenção a uma grande gama de fenômenos, desde a concepção, de alto nível, do significado de sentenças e textos inteiros a fenômenos de nível micro, como erros de ortografia. A atenção é como uma lente fotográfica multiuso, que pode, com flexibilidade, ampliar pequenos detalhes em um instante e, no 
momento seguinte, exibir um panorama mais amplo, além de poder manter ativas, ao mesmo tempo, múltiplas perspectivas de diferentes níveis, criando contextos dentro de contextos. Como os dados dos acionamentos de teclas e mouse podem ser representados com um grau flexível de refinamento, dependendo da duração selecionada para delimitação da pausa, tais dados podem fornecer evidências do processamento tanto de alto quanto de baixo nível, mas talvez sejam particularmente mais notáveis nos níveis inferiores.

Vale notar que a duração das pausas parece ser claramente estratificada. No processo de produção do tradutor em questão, os intervalos entre os acionamentos de teclas duraram, na maioria das vezes, cerca de $100 \mathrm{~ms}$. Inclui-se aqui excepcionalmente uma pausa de 234 ms, que (i) parece ser parte de uma reação complexa a um erro acidental de digitação e, (ii) apesar de inferior a $250 \mathrm{~ms}$, é indicativa de uma leve falta de fluência. Essa pausa teve mais que o dobro de duração da média dos intervalos entre os acionamentos de teclas nos momentos em que a digitação foi fluente. Na digitação do restante da expressão ("ldig•gesprochen"), a média dos intervalos entre os acionamentos de teclas foi menor que $100 \mathrm{~ms}$ (i.e., 15 acionamentos de teclas em $1404 \mathrm{~ms}$ ). No intervalo entre $250 \mathrm{~ms}$ e $900 \mathrm{~ms}$, houve somente oito pausas, das quais quatro foram associadas a edições simples e quatro, provavelmente, a monitoramento e tomadas de decisão mais complexas. Dentre as pausas mais longas, uma (entre os segmentos 4 e 5) foi excepcionalmente longa, mas as outras se deram, aproximadamente, no intervalo entre 0,9 e 1,5 s. Dessa forma, foram identificadas quatro categorias de pausas: (i) uma pausa excepcionalmente longa (1); (ii) cinco pausas de delimitação de segmentos (5); (iii) uma categoria intermediária (com duração entre 234 e $874 \mathrm{~ms}$ ) associada a edições e "reconsiderações" sobre outras alternativas (9); e (iv) pausas curtas entre acionamentos de teclas e outras ligeiramente mais longas entre palavras e morfemas (147), sendo a maioria na faixa de 80 a $200 \mathrm{~ms}$.

\section{Segmentação baseada em dados do olhar (gaze)}

Como todas as evidências utilizadas para embasar as ideias sugeridas neste artigo advêm de uma única gravação do processo de digitação de uma tradução para o alemão de apenas uma sentença extraída de uma pequena notícia de jornal em língua inglesa, não é possível generalizar as observações aqui apresentadas. A gravação mostra as mudanças no percurso do olhar (gaze) de um tradutor bastante hábil que executa sua tarefa com rapidez. A atividade analisada durou um pouco mais de $18 \mathrm{~s}$, iniciados aos dois minutos e quarenta 
segundos da tarefa, após três sentenças de um texto jornalístico que relatava o resultado de um julgamento. Trata-se de um ponto em que, após um início lento, o tradutor pareceu ter se familiarizado com a tarefa e aumentou consideravelmente a velocidade geral de digitação e de produção da tradução.

Do ponto de vista técnico, como será mostrado nas imagens das capturas de telas a seguir, a gravação não é das melhores. A calibração imprecisa fez com que as amostras do olhar e as fixações ficassem deslocadas horizontal e verticalmente. $\mathrm{Na}$ horizontal, os dados foram projetados para uma tela virtual que era mais estreita que a tela real. ${ }^{6}$ Isso significa que, para associar os círculos referentes às fixações às palavras que foram efetivamente fixadas e presumivelmente lidas, a posição desses círculos tem de ser deslocada para a esquerda ou para a direita dependendo da direção tomada partindo do centro em direção à margem mais próxima. $\mathrm{Na}$ vertical, pode-se observar o fenômeno oposto. Nesse eixo, as fixações estão acima da linha a que pertencem originalmente, na metade superior da tela (cada vez menos à medida que se aproximam do centro horizontal da tela), e abaixo da linha a que pertencem originalmente, na metade inferior (cada vez mais à medida que se afastam do centro horizontal). No entanto, a gravação é precisa o suficiente para nos permitir saber, com um alto grau de probabilidade, quais foram as palavras efetivamente olhadas. Nossa teoria de como é feita a leitura pode nos ajudar a decidir, em vários casos, a que palavra uma fixação deve ser associada. O conhecimento dos aspectos técnicos do rastreamento ocular também é extremamente importante. Felizmente, para os objetivos aqui propostos, os dados brutos são bastante claros no que diz a respeito a quando houve uma mudança no percurso do olhar entre as duas janelas - a janela superior (Win1), com o texto-fonte (TF); e a janela inferior (Win2), com o texto-alvo (TA).

Os segmentos delimitados com base nos acionamentos de teclas e mouse têm tamanhos variados. Em um registro de acionamentos de teclas, o menor segmento corresponde a um toque de teclado; um segmento um pouco maior pode ser um morfema ou uma sílaba; um segmento ainda maior pode ser uma palavra (constituída grafologicamente) etc., dependendo da duração e da distribuição dos intervalos entre os acionamentos de teclas. Com os dados do olhar, a situação é um pouco diferente. Um rastreador ocular registra a

\footnotetext{
${ }^{6}$ Além da observação da projeção global dos dados do olhar na tela, existem vários outros indícios que podem ajudar os pesquisadores a fazer os ajustes necessários para associar corretamente as fixações às palavras a partir de uma gravação com problemas de precisão. A reprodução dinâmica da gravação de um arquivo fornece vários desses indícios. Por exemplo, a representação estática na Figura 10 (mais à frente) mostra as fixações (na Win2) na palavra "Gerichtsverfahren"; porém, a reprodução dinâmica da gravação mostra claramente que, nesse ponto, o olhar estava na digitação de "des vierfachen".
} 
posição do olhar em relação à tela várias vezes por segundo, geralmente entre 60 e 2000 vezes (“amostras”) por segundo. É assim que a máquina funciona; no entanto, não é assim que um tradutor humano segmenta as informações. $O$ olho humano se move de uma fixação para outra, havendo um salto rápido entre elas, chamado de "sacada" ou "movimento sacádico". As fixações podem ser vistas, tecnicamente, como coleções de amostras, perfazendo tipicamente de 200 a 300 ms. Um leitor hábil não fixa um caractere por vez; normalmente, tem uma fixação por palavra de conteúdo. De um ponto de vista comportamental e cognitivo, portanto, pode-se dizer que o menor segmento de leitura (para um leitor hábil) é uma palavra de conteúdo, que em seguida é saltada por meio de um movimento sacádico.

No entanto, como os segmentos mínimos se combinam em unidades de processamento maiores, representadas por uma ou várias palavras, é de maior interesse do que os segmentos propriamente ditos. Sabe-se que, como escreveu Chesterman (1989, p. 5), “[t]raduzir é algo que as pessoas fazem com as palavras". A tradução começa e termina com representações verbais (palavras), mas ainda fica em aberto a forma como o tradutor vai das palavras na língua-fonte (LF) para a palavras na língua-alvo (LA). O processo de associação ou "mapeamento" entre as representações verbais de duas línguas não demanda somente considerações sobre palavras e restrições gramaticais que operam sobre elas; também demanda, em boa medida, considerações sobre o alinhamento mais adequado entre os significados dessas palavras - a(s) representação(ões) mental(is) evocada(s) por elas. "Quais palavras na LA expressarão da forma mais apropriada a representação mental ativada pelo texto-fonte?" Essa é a pergunta com a qual o tradutor se depara constantemente. De acordo com de Groot (1997, p. 29ff.), a tradução pode ser horizontal ou vertical. As palavras (formas das palavras) podem ser pareadas de forma bilíngue na memória do tradutor de tal modo que não ocorre comparação entre dois significados (tradução horizontal) ou, do contrário, o tradutor tem que encontrar um significado comparando e avaliando a palavra ou expressão na LF com uma ou várias palavras ou expressões da LA, de acordo com a capacidade delas de ativar significados similares. Será que os dados do olhar podem ajudar a fazer essa distinção?

A partir da observação do comportamento do olhar do tradutor em questão, ficou evidente que ele lê, em geral, sete palavras à frente (incluindo as "palavras-âncora") quando se trata de uma porção "nova" do TF. Essa estratégia de leitura do TF pode ser caracterizada como uma leitura esparsa para adiante, em que o tradutor geralmente lê só a quantidade de texto-fonte necessária para obter uma porção de texto traduzível. Essa estratégia envolve riscos consideráveis, visto que mais adiante na sentença do TF podem surgir informações que 
forçarão o tradutor a excluir, alterar ou rearranjar um texto já traduzido e digitado. Para um digitador rápido, pode haver uma razão cognitiva para enfrentar riscos calculados dessa natureza. Uma vez que uma unidade traduzível foi lida e traduzida, a capacidade cognitiva é liberada e fica disponível para a próxima unidade traduzível. O cálculo possivelmente inconsciente e rotinizado parece ser que a vantagem de liberar capacidade cognitiva é maior que o risco incorrido, ou seja, maior que a penalidade de ter que revisar o texto já produzido.

Outra vantagem possível advinda desse método em que se coordenam leitura e digitação é que, quando não há obstáculos particulares à tradução, a leitura esparsa permite que o tradutor/digitador mantenha uma produção textual razoavelmente fluente e rápida. No trecho selecionado para análise, como será visto a seguir, essa estratégia encontrou obstáculos, mas eles foram rapidamente superados sem desvio à estratégia de leitura esparsa.

A seção a seguir apresenta um relato detalhado do percurso do olhar do tradutor pelo TF e pelo TA durante os $18,5 \mathrm{~s}$ que ele levou para traduzir a sentença em pauta. O percurso do olhar será ilustrado por meio de oito capturas de tela (Figuras 4-11), as quais, infelizmente, não mostram a dinâmica dos movimentos do olhar. Espera-se, contudo, que as legendas e os comentários ajudem a ilustrar as principais direções e sequências dos movimentos do olhar.

\section{Narrativa analítica dos dados do olhar (gaze) durante a tradução da quarta sentença}

Depois de mover o olhar para cima, para a Win1 (Mudança 1), para fixar a primeira palavra ("Yesterday" ["Ontem"]) da sentença sob escrutínio (sentença 4 do texto), o tradutor estava pronto para digitar a tradução em alemão ("Gestern") e começou a fazê-lo enquanto continuava a ler mais material textual novo ("he was found guilty of four" ["ele foi considerado culpado em quatro"]), conforme mostrado na Figura 4. Em outros termos, ao que parece, a palavra "Yesterday" foi percebida como uma unidade traduzível independente, já que a tradução de tal palavra começou a ser digitada enquanto era feita a leitura de material textual novo para a obtenção da unidade traduzível completa (ou subsequente). Uma "unidade traduzível" é uma noção estritamente subjetiva. Corresponde ao que o tradutor compreende como a quantidade de texto suficiente para dar início à tradução de dado excerto. A interpretação de que o tradutor tratou a palavra "Yesterday" como uma unidade traduzível independente é subsidiada pelo fato de a digitação de "Gestern" ter começado imediatamente depois de a palavra ter sido lida. Esse é um exemplo clássico de uma tradução horizontal. Não obstante, a leitura prosseguiu na Win1 sem qualquer mudança no percurso do olhar para a janela do TA (Win2), o que sugere que, apesar de poder ser traduzido diretamente, o trecho 
(também) foi percebido como parte de uma unidade traduzível maior. $\mathrm{O}$ arquivo da gravação aqui analisada tem como denominação P01_T1.xml e se encontra dentro do experimento SG12. A leitura na Win1 procedeu até o fim da linha, de modo que, ao todo, sete novas palavras foram lidas nessa primeira busca por material textual novo. Com o trecho "he was found guilty of four [??]”, o tradutor dispunha dos elementos estruturais básicos da oração principal - sujeito (“he"), verbo na voz passiva ("was found”) e complemento verbal ("guilty of four [??]") -, mas tinha um desafio estrutural, visto que, em alemão, o verbo principal, nesse caso, só será introduzido ao final da oração.

Obviamente, é sempre necessário ler alguma porção do TF para se ter o que traduzir. Essa motivação fundamental para uma mudança do percurso do olhar para o TF está ilustrada nessa primeira atividade de leitura. Nela, o tradutor leu o TF novo até que tivesse processado e construído um significado suficiente para formar o que ele considerou ser uma unidade traduzível. Como será visto, houve dois novos processos de leitura com o objetivo similar de coletar material textual novo. Em outros termos, a sentença sob escrutínio foi lida em três movimentos para adiante relativamente curtos: o segundo adicionou três novas palavras; o terceiro, quatro.

A primeira sequência também mostra que o tradutor foi capaz de digitar na Win2 sem tirar o olhar da janela do TF (Win1). Essa sobreposição de leitura e produção escrita é vista como um indicativo de processamento paralelo (BALLING et al., 2014, p. 232) e pode muito bem ser esse realmente o caso. Pode-se dizer com segurança que a combinação dos dados do olhar com os dados dos acionamentos de teclas evidencia que o tradutor, com frequência, lia e digitava ao mesmo tempo, visando, de forma sistemática, assegurar que a leitura de material textual novo levasse os dedos no teclado a não ter que esperar por algo a ser digitado.

Após ter lido "Yesterday, he was found guilty of four" e digitado concomitantemente "Gester", porém ainda sem o " $n$ " final, o tradutor desceu sua atenção visual para a Win2 (Mudança 2). Uma mudança de atenção para a janela do TA pode ter vários propósitos. Neste caso, o objetivo mais óbvio foi assegurar que o TA estava sendo produzido como o tradutor planejava e esperava, visto que estava digitando "às cegas", isto é, sem atenção visual concomitante (sem "monitoramento visual"). ${ }^{7}$

7 O monitoramento visual é somente um dos tipos de monitoramento que pode estar ativo. Um digitador treinado, em geral, é bastante sensível às respostas táteis das pontas dos dedos. 
Figura 4 - Período de tempo representado: de 160.112 a $161.298 \mathrm{~ms}$

Killer nurse receives four life sentences
Hospital nurse Colin Norris was imprisoned for life today for the killing of four of his atients. 32.
killed the four women in 2002 by giving them large amounts of sleeping medicin festerday, he was found guilty of four
counts of murder following a long trial. He was given four life sentences, ong forjeach of the killings. He will have to serve at
least 30 years. Police officer Chris Gregg said that Norris had been acting strangely around the hospital. Only the awareness
of other hospital staff put a stop to him and to the killings. The police have learned that the motive for the killings was that
Norris disliked working with old people. All of his victims were old weak women with heart problems. All of them could be
considered a burden to hospital staff.
Krankenpfleger des Todes wird vierfach zu Lebenslänglich verurteilt
Der im Krankenhaus angestellte Krankenpfleger Colin Norris wurde für den Mord an vier seiner Patienten heute zu einer
lebenslänglichen Gefängnisstrafe verurteilt. Der 32-jährige Norris aus Glasgow tötete die vier Frauen 2002 , indem er ihnen
große Mengen an Schlafmedikamenten verabreichte. Gester

Nota: Os círculos representam fixações. Os pontos verdes representam amostras do olho direito; e os pontos vermelhos, do olho esquerdo. Vejam-se os comentários anteriores sobre o deslocamento das representações das fixações. O olhar do tradutor primeiro subiu da posição do cursor na Win2 (Mudança 1) para fixar a palavra "Yesterday" no TF (Win1). Depois, as fixações se deram em "he was found guilty of four" enquanto o tradutor digitava "Gester" na Win2, sem apresentar atenção visual nessa área. No final dessa sequência, de 1,2 s de duração, o olhar desceu para a Win2, como pode ser visto nos pontos de amostragem, desde a fixação da extrema direita na Win1 até a posição do cursor na Win2 (depois de "Gester").

$\mathrm{Na}$ Win2 (Figura 5), o tradutor deu atenção visual primeiro à digitação de "(Gester)n wurde" ["Ontem foi”]. Novamente, a mudança na atenção visual para a Win2 teve como objetivo assegurar que a digitação estava sendo realizada corretamente (monitoramento visual da atividade de digitação). Essa verificação durou $0,7 \mathrm{~s}$. Nesse ponto, no qual a digitação também se mostrou hesitante (em torno do sujeito "er"), o tradutor claramente não dispunha de tudo o que precisava para traduzir e, portanto, precisou ler mais do TF; assim, o olhar moveu de volta para a Win1 (Mudança 3) para a leitura daquilo de que o sujeito "he" estava sendo considerado culpado. Após reler "found guilty of four", de modo a poder ancorar o próximo material textual novo ao já lido, o tradutor mudou o olhar para a esquerda, indo para o início da linha seguinte, onde pôde ler "counts of murder" ["acusações de homicídio"] pela primeira vez. Dessa vez, foram lidas seis palavras de uma vez, das quais somente as últimas três não haviam sido lidas antes. Nesse ponto, o tradutor parou a leitura - após ter capturado uma unidade traduzível adicional -, e o seu olhar começou a descer para a posição do cursor 
na Win2 (Mudança 4), onde "er" tinha sido digitado de forma hesitante em continuidade à tradução do que era traduzível e executável na unidade anterior.

Novamente, o objetivo da mudança do olhar para o TF na Win1 foi buscar conteúdo novo. A necessidade de ler mais do TF surgiu logo após a tradução de "Yesterday, he was" (“Gestern wurde er") ter sido pensada e digitada, uma vez que a tradução da parte principal da unidade traduzível anteriormente encontrada ("found guilty") não poderia ser feita imediatamente após a sua leitura. Isso acontece devido às restrições sintáticas do alemão, em que primeiro deveria vir aquilo de que o sujeito "er" fora considerado culpado. Em uma atitude típica desse tradutor (e de muitos outros), a leitura de material textual novo foi feita da seguinte forma: primeiro, foi feita uma leitura do texto que já tinha sido lido anteriormente, a fim de "ancorar" material textual novo ao antigo; em seguida, deu-se continuidade à leitura, até que uma nova unidade traduzível fosse encontrada.

Figura 5. Período de tempo: de 161.320 a $163.482 \mathrm{~ms}$

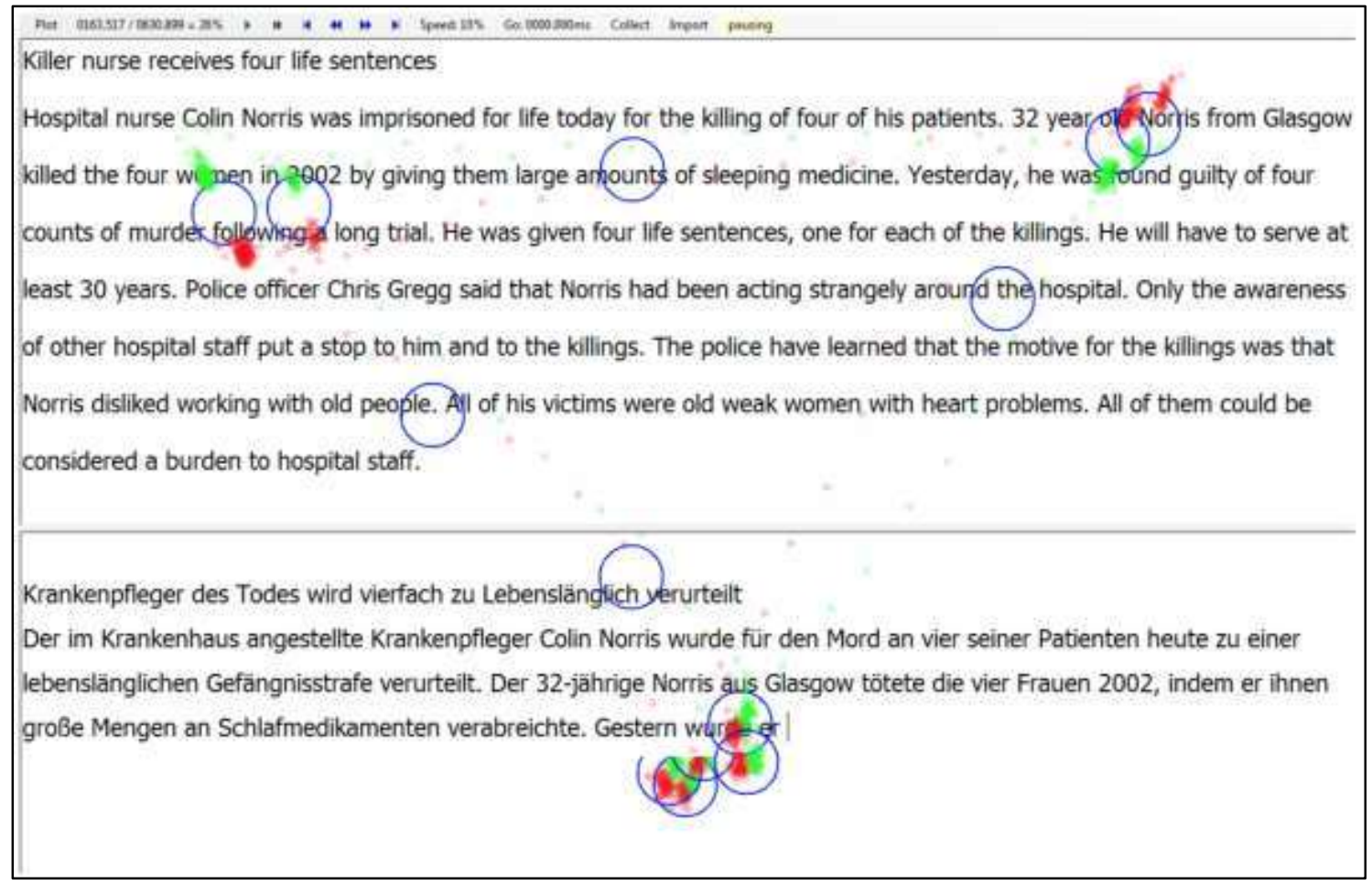

Nota: Após a Mudança 2 - para a posição do cursor depois de "Gester" na Win2 -, o tradutor monitorou visualmente a digitação de "(Gester)n wurde" durante $0,7 \mathrm{~s}$ (três fixações na extrema esquerda); em seguida, direcionou o olhar (Mudança 3) para "guilty of four", na Win1; depois, passou o olhar para a esquerda, em "counts of murder"; por fim, desceu o olhar novamente (Mudança 4) para a posição do cursor, após "er" (que havia sido digitado nesse ínterim), a fim de fixar em "wurde er", como preparação para usar tais palavras como âncoras para o que viria a seguir. 
Após fixar em "wurde er" (Figura 5) como âncora para novo material textual a ser traduzido, mas não dispondo ainda de um novo texto para inserção, o tradutor (i) ou sentiu a necessidade de refrescar a memória de curto prazo quanto àquilo de que o sujeito "he" tinha sido considerado culpado, ou (ii) esperava que olhar diretamente para as palavras prestes a serem traduzidas lhe ajudaria a ativar uma tradução para elas. Portanto, em vez de digitar algo, o tradutor, em seguida, direcionou o olhar novamente (Mudança 5) para reler "counts of murder" (Figura 6). Esse processo mostra uma segunda razão para mudar o percurso do olhar para o TF: a necessidade de refrescar a memória a respeito de algo já lido (mesmo que recentemente), olhando diretamente para uma palavra ou sintagma possivelmente como uma estratégia para ativar uma solução tradutória. Com o olhar ainda em "counts of murder" na Win1, o tradutor digitou "des vierfach" (para o planejado "des vierfachen Mordes" ["em quatro acusações de homicídio"]) sem qualquer atenção visual na Win2.

Figura 6 - Captura de tela da reprodução do olhar de 163.498 a 165.399 ms, mostrando que a digitação de “des vierfach(en Mordes)" foi realizada na Win2 (sem atenção visual) enquanto "counts of murder" recebia atenção visual na Win1.

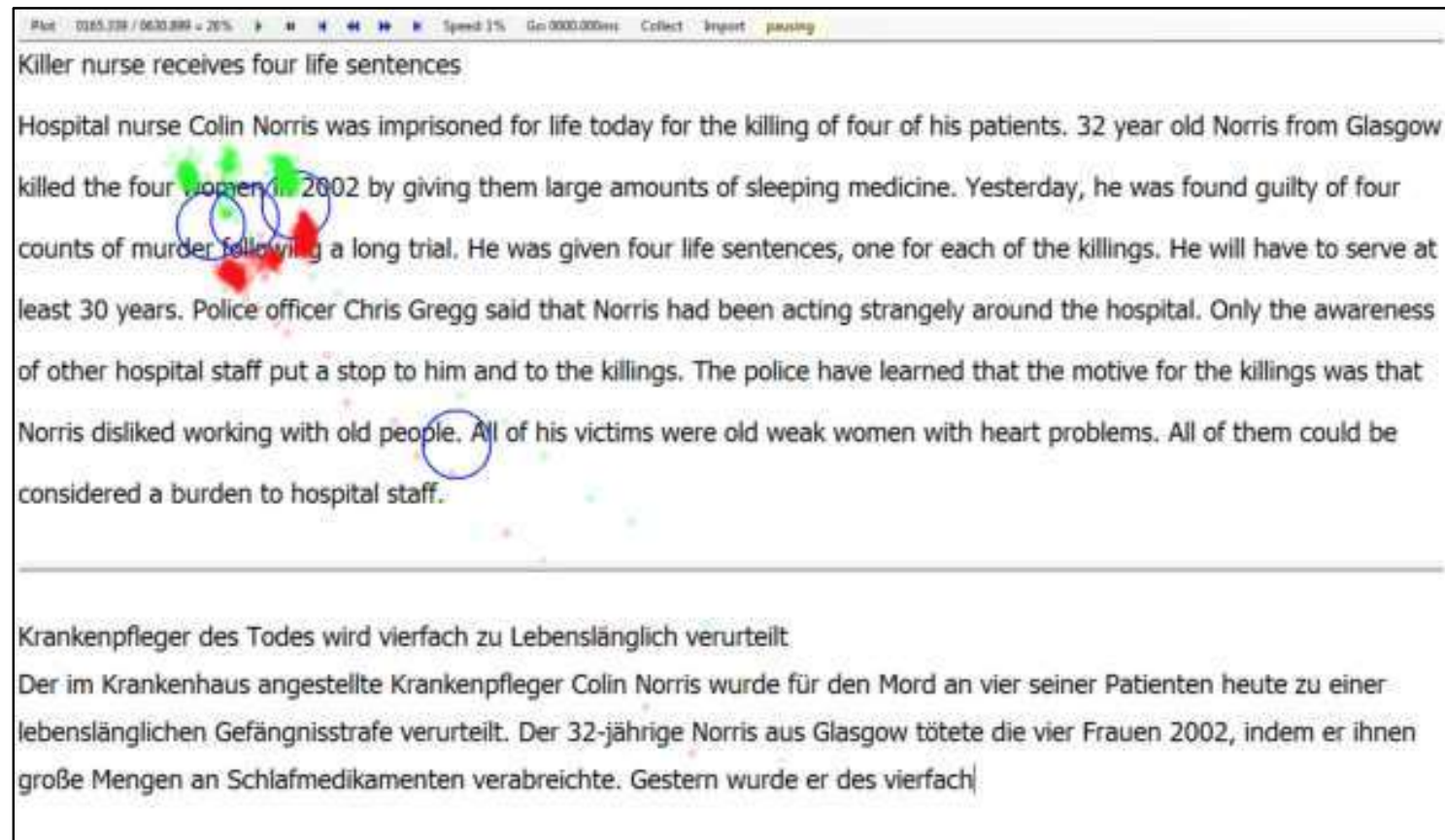

A Figura 7 apresenta os dados da Figura 6 e inclui as duas fixações novas, durante as quais o tradutor leu "following a long trial" ["ao cabo de um longo julgamento"] pela primeira vez. $\mathrm{O}$ tradutor em questão, como lhe parece ser de rotina, começou a ler adiante em busca da unidade traduzível subsequente enquanto ainda estava digitando a tradução da unidade anterior. A primeira fixação durou $316 \mathrm{~ms}$; a segunda, $493 \mathrm{~ms}$. Ambos os valores 
foram maiores que a média de duração das fixações, o que indica que a leitura foi particularmente intensa nesses casos e possivelmente acompanhada de surpresa e grande esforço mental. Ambas as fixações ocorreram enquanto o adjetivo "vierfachen" ["quádruplo"] estava sendo digitado na Win2. Pode-se assumir que a atividade de digitação concomitante às fixações teve um efeito de prolongação da duração dessas fixações, o que não ocorreu em outros casos na tradução; assim, a atenção claramente estava elevada nesse caso. Como pode ser visto na captura de tela, a atividade de leitura, em um primeiro momento, não interrompeu a digitação que estava em curso, a qual continuou em alta velocidade, de quase dez toques por segundo. No entanto, a digitação parou antes que o " $s$ " final, marca de genitivo, fosse adicionado à palavra "Morde". O processamento intenso ocorrido durante as duas novas fixações na Win1 resultou na decisão de mudar o percurso do olhar para a Win2 (Mudança 6) e ler novamente uma parte do TA que o tradutor, nesse momento, decidiu que precisava de revisão. Esse processo elucida outra função das mudanças de percurso do olhar da Win1 para a Win2: ler o TA para editá-lo.

Figura 7. Captura de tela da reprodução do olhar de 163.498 a $166.258 \mathrm{ms,} \mathrm{mostrando} \mathrm{duas} \mathrm{fixações} \mathrm{(na}$ Win1) adicionais àquelas da Figura 6, no trecho "following a long trial", enquanto a digitação de "(vierfach)en Morde" ocorria de forma concomitante e sem atenção visual.

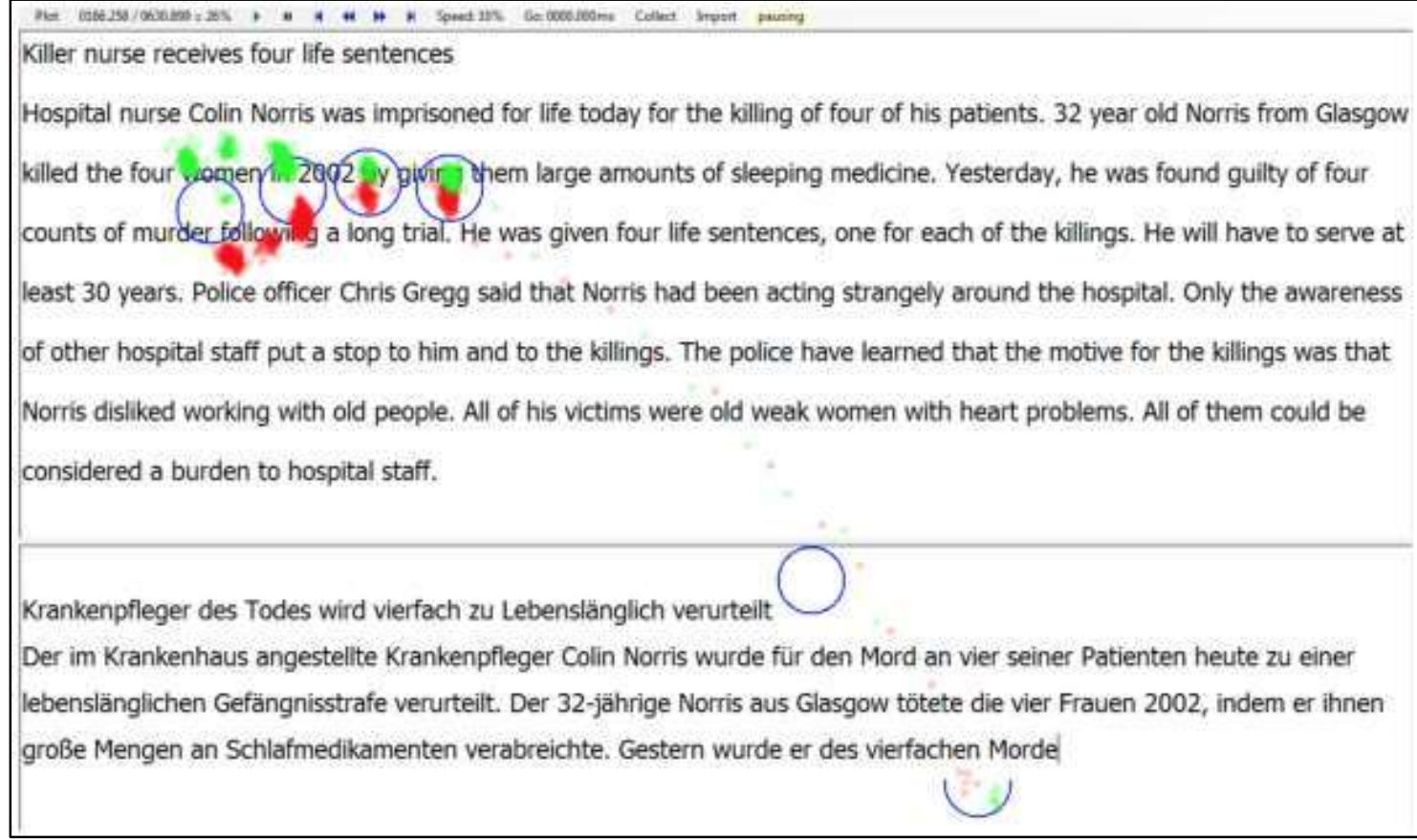

Nota: Após ler o novo trecho, o tradutor decidiu mudar o olhar (Mudança 6) para a posição do cursor na Win2, a fim de verificar o TA que havia sido digitado por último.

Depois que o trecho "wurde er des vierfachen Morde" foi lido e relido durante um pouco mais de 1,5 s e antes que o " $s$ " final fosse adicionado à palavra "Morde", o tradutor 
decidiu excluir "des vierfachen Morde" para que a tradução de "following a long trial" (guardada na memória de curto prazo) pudesse ser inserida primeiro.

Figura 8 - Captura de tela de 166.258 a 175.702 ms mostrando que, após repetidas leituras de "wurde er des vierfachen Morde" (1,5 s), uma nova solução levou à exclusão dessas palavras

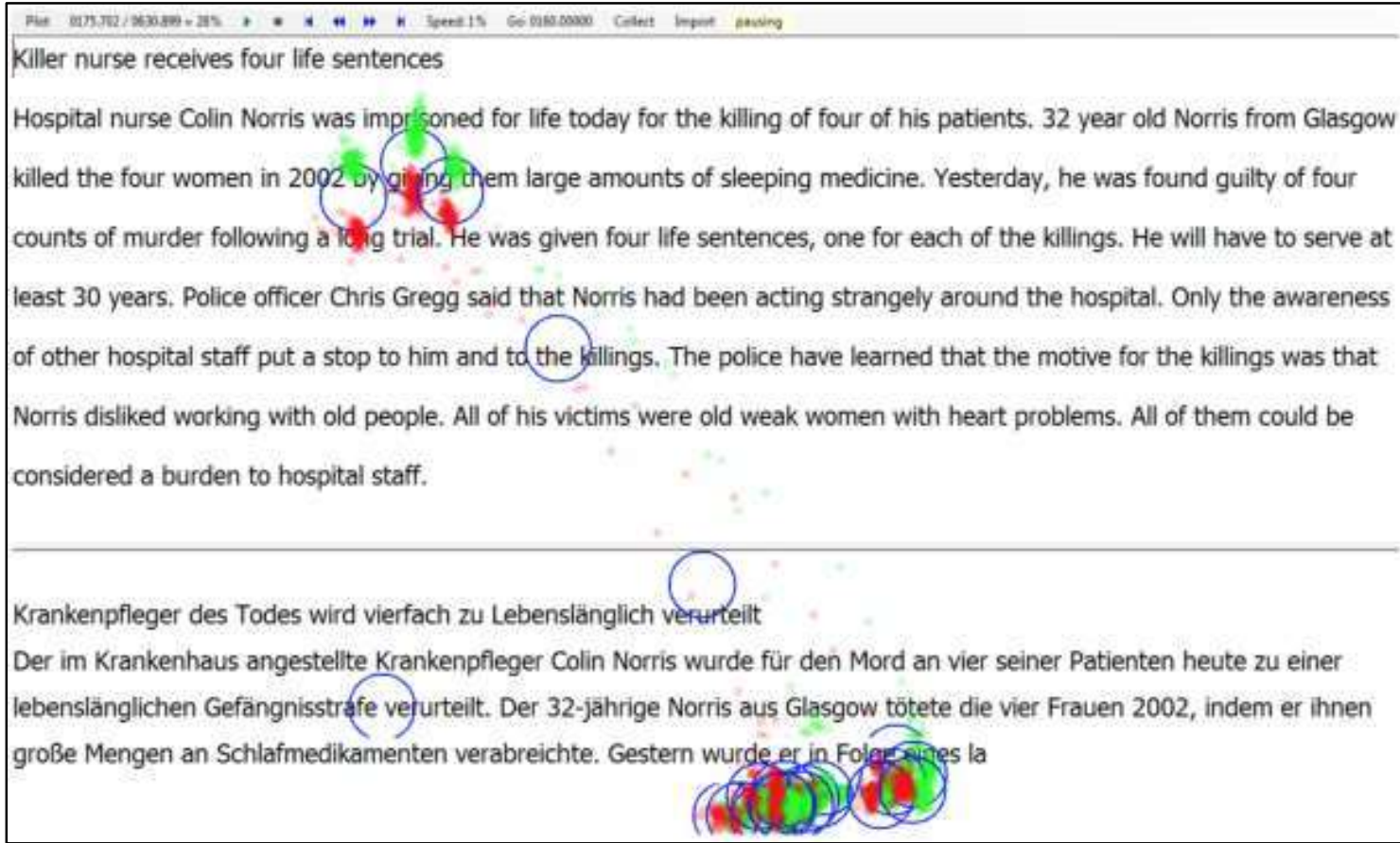

Nota: No lugar, foi digitada a expressão "in Folge", seguida por uma mudança de percurso do olhar (Mudança 7) para a Win1 para a releitura do trecho "following a long trial", com a digitação concomitante de "eines la".

A primeira versão em que o tradutor pensou parece ter sido "in Folge eines langen Gerichtsverfahren"; tanto que, após 2 s, "in Folge" foi digitado com monitoramento visual. A escolha por "in Folge" pode ter advindo da similaridade grafológica entre "following" e "Folge" e parece ser ilustrativa do impulso mimético que os tradutores nem sempre conseguem inibir com eficácia, algo que remete à ideia de "tradução literal" como procedimento padrão, aventada por Ivir (1981) e investigada por Tirkkonen-Condit (2005) e outros pesquisadores.

Depois de excluir "des vierfachen Morde" e digitar "in Folge", o tradutor mudou o olhar brevemente para a Win1 (Mudança 7) a fim de relembrar o que vem depois de “following" (Figura 8). Normalmente, o olhar era ancorado primeiro na palavra já traduzida da qual o tradutor se lembrava ("following"), antes de ser direcionado para o trecho ("a long trial") que precisava ser refrescado na memória de curto prazo. Essa atualização de informações levou 1,1 s e foi seguida imediatamente pela digitação de "eines la" e por uma mudança de percurso do olhar (Mudança 8) para a Win2; no entanto, ao contrário do 
esperado, não foi dada continuidade à atividade de digitação de "(eines la)ngen Gerichtsverfahren". A tradução foi interrompida; e deu-se início a uma leitura e releitura intensa da solução recém-digitada. O tradutor, obviamente, não estava satisfeito com a solução encontrada, mas não conseguiu algo melhor de imediato. Depois de uma leitura intensa por mais de 4 s, o tradutor finalmente decidiu por excluir a expressão "in Folge" e substituí-la por outra solução (cf. Figura 9).

A função da Mudança 7, de forma semelhante àquela da Mudança 5, parece ter sido a de manter claramente o foco no fragmento do $\mathrm{TF}$ em processamento durante a tradução. Muitos tradutores parecem gostar de dar uma nova olhada, rápida, no trecho do TF que está sendo traduzido, fazendo com que o intervalo de tempo entre o olhar e o toque do teclado seja bastante curto. Timarová et al. (2011, p. 132; cf. também DRAGSTED; HANSEN, 2008, p. 18) também encontraram valores curtos para o intervalo de tempo entre o olhar e o toque do teclado durante a última fixação em um grupo de tradutores profissionais. O fraseado exato de uma unidade traduzível do TF parece perder rapidamente seu vigor na memória de curto prazo; assim, é frequente encontrar esse comportamento do olhar, em que o tradutor revisita visualmente o trecho relevante do TF imediatamente antes de digitar sua tradução.

A Mudança 8 não foi feita para monitorar o texto já digitado ou sendo digitado, visto que o texto recém-digitado já havia sido verificado e nenhum material textual novo estava sendo digitado. Esse processo mostra como a atenção do tradutor se moveu para a leitura e a avaliação da solução recém-digitada, mas ainda não totalmente aceita.

Assim que a nova solução foi encontrada, com "nach" substituindo "in Folge", o tradutor rapidamente digitou "nach langem Gerichtsverfahren" sem mudar o percurso do olhar para atualizar o conteúdo na memória de curto prazo. Em vez disso, o tradutor monitorou visualmente a digitação da nova solução, como que para se assegurar de que ela estava sendo resgatada da sua memória de forma apropriada e certificar-se de que ela colocaria fim àquele interlúdio de esforço de processamento. 
Figura 9 - Captura de tela de 175.702 a 181.829 ms, mostrando a solução "nach" para "following" e o direcionamento do olhar (Mudança 9), ao final, para a Win1 ("he was found guilty")

Killer nurse receives four life sentences
Hospital nurse Colin Norris was imprisoned for life today for the killing of four of his patients
killed the four women in 2002 by giving them large amounts of sleeping medicine. Yesterday, he was found guilty of four
counts of murder following a long trial. He was given four life sentences, one for each of the killings. He will have to serve at
least 30 years. Police officer Chris Gregg said that Norris had been acting strangely arounct the hospital. Only the awareness
of other hospital staff put a stop to him and to the killings. The police have learned that the motive for the killings was that
Norris disliked working with old people. All of his victims were old weak women with heart problems. All of them could be
considered a burden to hospital staff.
Krankenpfleger des Todes wird vierfach zu Lebenslänglich verurteilt.
Der im Krankenhaus angestellte Krankenpfleger Colin Norris wurde für den Mord an vier seiner Patienten heute zu einer
lebenslänglichen Gefängnisstrafe verurteilt. Der 32-jährige Norris aus Glasgow tötete die vier Frauen 2002, indem er ihnen
große Mengen an Schlafmedikamenten verabreichte. Gestern wurde er nach langem Gerichtsverfahren

Depois da decisão por "nach", a estrutura da sentença já estava estabelecida e faltava apenas digitar o restante da tradução, com somente três breves revisitações visuais aos trechos relevantes do $\mathrm{TF}$, que já haviam sido lidos várias vezes e só precisavam ser rapidamente relembrados.

Havia dois pequenos erros de digitação no começo da palavra "Gerichtsverfahren", os quais foram notados e corrigidos imediatamente. Quando faltavam ser digitadas apenas as últimas cinco letras dessa palavra ("ahren"), o percurso do olhar passou para a Win1 (Mudança 9) para a releitura de "he was found guilty" (Figura 9).

Tendo lido até esse ponto do texto, o percurso do olhar do tradutor passou para a Win2 (Mudança 10) para monitorar a digitação da tradução de "of four" ("des vier"). Embora o tradutor tivesse traduzido anteriormente a unidade ("des vierfachen Morde[s]") e tivesse acabado de ter uma visão parafoveal de "four", o olhar voltou novamente para a Win1 depois de 1,4 s (Mudança 11), para realizar uma releitura (pela terceira vez) de "guilty of four counts of murder", antes de as últimas seis letras de "vierfachen" serem digitadas. 
Figura 10 - Captura de tela de 181.829 a $183.831 \mathrm{ms,} \mathrm{mostrando} \mathrm{a} \mathrm{mudança} \mathrm{inicial} \mathrm{do} \mathrm{percurso} \mathrm{do} \mathrm{olhar}$ para a Win2 (Mudança 10), monitorando a digitação de "des vier", e o retorno do olhar para a Win1 (Mudança 11) para a releitura de "he was found guilty of four counts of (murder)"

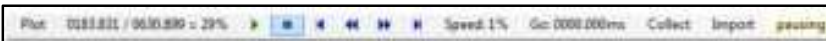

Killer nurse receives four life sentences

Hospital nurse Colin Norris was imprisoned for life today for the killing of four of his patients. 32 year fld Norns from Glasgow killed the four women in 2002 by giving them large ahounts of sleeping medicine. Yesterday, he was found guilty of four counts of murder folowing a long trial. He was given four life sentences, one for each of the killings, He will have to serve at least 30 years. Police officer Chris Gregg said that Norris had been acting strangely around the hospital. Only the awareness of other hospital staff put a stop to him and to the killings. The police have learned that the motive for the killings was that Norris disliked working with old people. All of his victims were old weak women with heart problems. All of them could be considered a burden to hospital staff.

Krankenpfleger des Todes wird vierfach zu Lebenslänglich verurteilt

Der im Krankenhaus angestellte Krankenpfleger Colin Norris wurde für den Mord an vier seiner Patienten heute zu einer lebenslänglichen Gefängnisstrafe verurteilt. Der 32-jährige Norris aus Glasgow tötete die vies Fraen 2002, indem er ithnen große Mengen an Schlafmedikamenten verabreichte. Gestern wurde er nach langem Gerichtsverfahren des vierfachen

Com o olhar ainda na Win1 enquanto a palavra "Mordes" estava sendo digitada na Win2 - agora, pela primeira vez, com o " $s$ " final (Figura 11) -, o tradutor continuou a leitura de toda a expressão "following a long trial" e depois deslocou o olhar para a direita, para "Yesterday, he was found guilty" (pela quarta vez), como forma de preparação para a digitação das duas últimas palavras da tradução. Um erro acidental ("schg”) na digitação de "schuldig" ["culpado"] foi notado instantaneamente por meio de resposta tátil e levou o percurso do olhar para a Win2 (Mudança 12) para monitoramento da correção e da digitação adicional de "schuldig gespro(chen)" ["considerado culpado"]. As demoras ocorridas entre os acionamentos de teclas antes de " $u$ " e " $l$ " indicam o esforço cuidadoso do tradutor em corrigir a palavra de forma adequada. Anteriormente, durante a digitação de "Gerichstverfahren", a atenção visual foi direcionada para a digitação acidental da letra " $F$ ", mas o ajuste do olhar desse processo foi tão discreto que se fundiu com o monitoramento visual da tela no local onde a digitação estava ocorrendo naquele momento. Esse é o mesmo caso de quando a sílaba "Ver" (de "Verfahren") foi digitada e, em seguida, instantaneamente modificada para “Gerichtsverfahren". No entanto, no caso da digitação não intencional da letra " $g$ " (em "schg"), fica evidente que um erro de digitação acidental percebido por resposta tátil pode gerar uma mudança do percurso do olhar para a cena do incidente na Win2. 
Por fim, seguindo o padrão já apontando para esse tradutor, o percurso do olhar se moveu para a Win1 (Mudança 14) enquanto ainda faltavam quatro acionamentos de teclas para a digitação da palavra "gesprochen", e o tradutor já estava buscando identificar a(s) próxima(a) unidade(s) traduzível(is) na sentença subsequente do TF ("He was given four life sentences" ["Ele recebeu quatro sentenças de prisão perpétua"]).

Figura 11 - Captura de tela 0188.480/0630.899

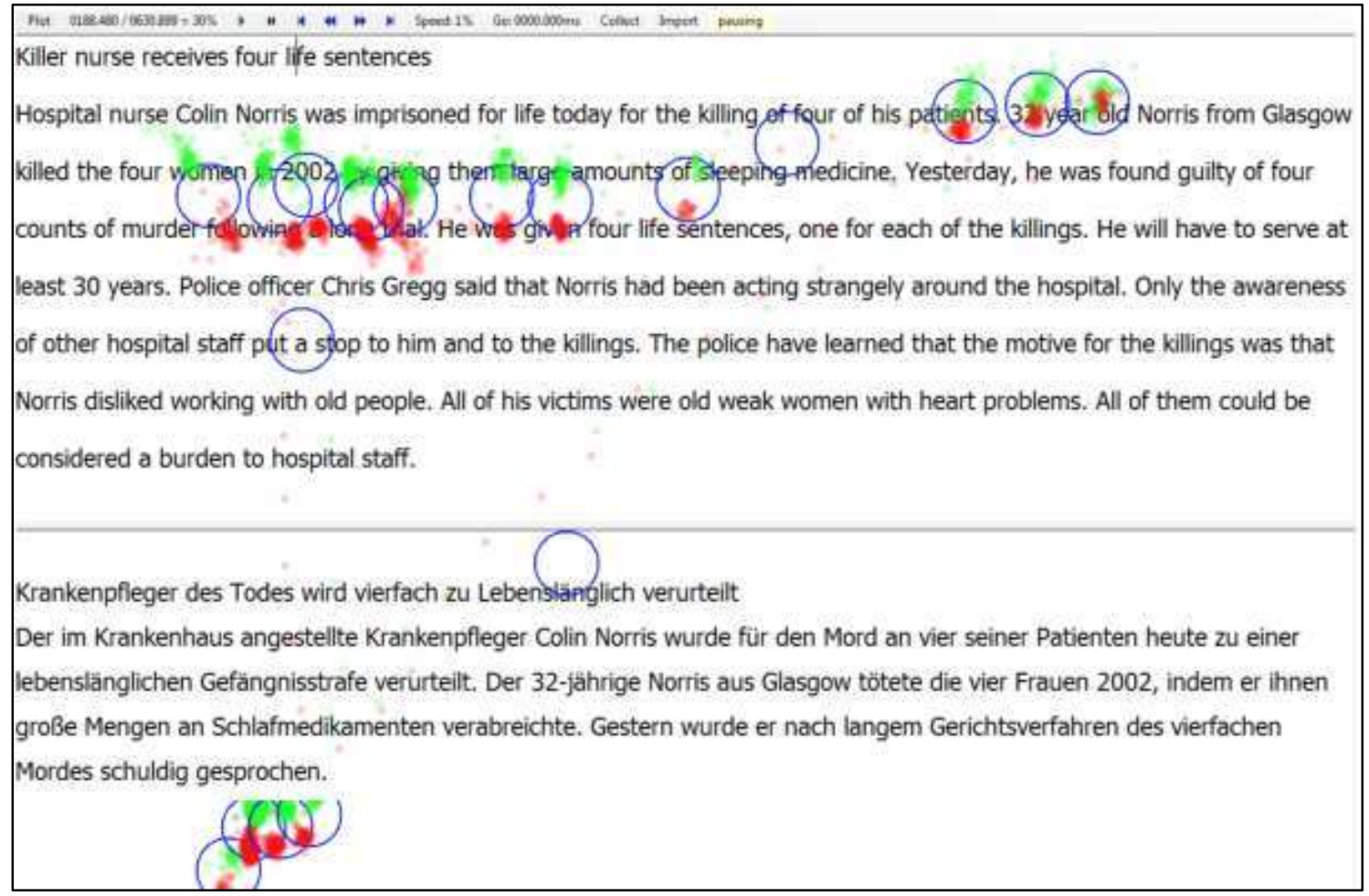

Nota: No final da digitação (sem monitoramento visual) da palavra "Mordes", com o olhar em "counts of murder following", o olhar (ainda na Win1) voltou-se para a direita, para "Yesterday, he was found guilty", como preparação para a digitação de "schuldig gesprochen". Um erro de digitação em "schuldig" levou o olhar para baixo, indo para a Win2 (Mudança 12). Enquanto as últimas quatro letras da última palavra estavam sendo digitadas, o olhar foi direcionado novamente para a Win1 (Mudança 13), para a leitura da primeira oração da sentença subsequente, a qual foi ancorada às últimas palavras da sentença anterior, "long trial".

\section{Discussão e considerações preliminares}

Diferentemente do intérprete simultâneo, que depende da taxa de palavras por segundo ou minuto pronunciadas por outra pessoa, um tradutor, ao produzir uma tradução escrita, pode definir o ritmo da leitura e reler o texto quantas vezes quiser, se julgar necessário. Um tradutor pode também controlar livremente a quantidade de material textual do TF que lerá 
antes de traduzir. Isso significa que o estilo de leitura e escrita do tradutor pode refletir diretamente o seu perfil cognitivo e suas preferências individuais.

No trecho analisado na seção anterior, a partir de uma gravação que continha alguns problemas técnicos de calibragem, mas ainda assim evidenciava as atividades do olhar e dos acionamentos de teclas referentes à tradução de uma única sentença, afirmou-se que as mudanças no percurso do olhar foram motivadas por diferentes necessidades e finalidades. A Mudança 1 para a Win 1 teve como objetivo buscar uma nova unidade traduzível do TF. Esse também foi o objetivo das Mudanças 3 e 5, que foram seguidas pela releitura de trecho do TF que já havia sido lido antes e pela subsequente leitura de material textual novo (de forma a ancorar o material textual novo no anterior). Com a leitura que sucedeu a Mudança 5, houve a leitura de toda a sentença do TF. Portanto, o objetivo da leitura subsequente não foi ler material textual novo, mas sim ter uma visão direta, ou mais recente, do segmento que estava sendo traduzido, especialmente onde a tradução demandava uma reestruturação sequencial das unidades traduzíveis. Assim, a releitura de "following a long trial" depois da Mudança 7 foi motivada pela decisão do tradutor por excluir a tradução de "of four counts of murder" e inserir primeiro a tradução de "following a long trial". Para assegurar que essa operação fosse realizada com sucesso, o tradutor olhou novamente para a unidade traduzível relevante antes de digitar a tradução correspondente. A mesma motivação parece ter impulsionado a releitura, ocorrida depois da Mudança 9, do trecho "he was found guilty of four", que foi instantaneamente seguida pela digitação da tradução para "of four". Por fim, a leitura na Win1, na Figura 11, ilustra a leitura final do tradutor de toda a sentença para assegurar que tudo estava sendo incluso antes de se partir para uma nova sentença.

Foram identificados dois tipos de atenção visual na Win2. O tipo mais comum foi a atenção visual dada ao texto em construção (monitoramento visual da digitação) - por exemplo, quando da digitação de "wurde" (Figura 5), "in Folge" (Figura 8), "nach langem Gerichtsverf(ahren)" (Figura 9), "des vier(fachen)" (Figura 10) e "(sch)uldig gespro(chen)" (Figura 11). Há motivos para se supor que essa atenção visual em nada impediu um processamento concomitante da tradução - por exemplo, na forma de contínua descoberta de soluções, como visto na rápida execução da mudança de "Ver(fahren)" para "Gerichtsverfahren" durante o período de atenção visual na Win2, onde a digitação estava sendo monitorada (Figura 9 e Figuras 1 a 3).

O segundo tipo de atenção visual na Win2 incluiu a leitura de material textual já traduzido. Isso ocorreu quando o tradutor percebeu que algo não estava certo. A leitura 
repetida de "wurde er des vierfachen Morde" (Figura 8) precedeu a decisão de excluir "des vierfachen Morde". A nova solução ("wurde er in Folge eines la") passou por uma releitura similar, ainda mais intensa e crítica, que durou mais de $4 \mathrm{~s}$ antes de também ser rejeitada. Por fim, em um nível mais superficial, a atenção também foi direcionada para a Win2 em caso de percepção de erro de digitação cuja correção precisava de uma atenção visual rigorosa.

A motivação principal que direciona o olhar do tradutor para a janela do TF é a necessidade de encontrar material textual novo para traduzir. Com duas janelas na tela, como em muitas configurações de programas para tradução, encontrar a próxima unidade traduzível parece envolver uma redundância considerável, pois geralmente se lê muito mais material textual do que parecer ser estritamente necessário. A leitura ocorre antes da nova unidade e pode ocorrer além dela. Não obstante, como já foi sugerido, a leitura de material textual anterior, na maioria das vezes, serve ao propósito de ancorar material textual novo ao anterior. Dessa forma, asseguram-se uma leitura correta e coerente do novo material do TF e a inserção apropriada de material textual novo ao já produzido no TA.

Um segundo direcionador importante da atenção visual para o TF é a necessidade de o tradutor dar uma nova olhada na representação da unidade do TF cuja tradução está prestes a ser digitada ou, mesmo, está sendo digitada. O que o tradutor lembra das representações do TF parece esvair-se com rapidez ou deixar, rapidamente, de ser acessado com o imediatismo desejado na memória do tradutor. A presença cognitiva constante do TF é, ao mesmo tempo, necessária e não de todo desejável, devido ao seu potencial negativo de pré-ativação, ou priming (i.e., influência indesejada de um evento antecedente sobre um evento posterior, intencionado). Ela é necessária porque, no ato da tradução, deve coexistir mental e temporalmente (de alguma forma) com uma solução-alvo. É, contudo, indesejável porque uma forte presença da representação escrita acarreta um risco de pré-ativação das opções de tradução sugeridas primeiro ao tradutor por meio de uma similaridade formal entre LF e LA, devendo o tradutor suprimir essa pré-ativação para evitar uma interferência indesejada.

A motivação principal da atenção visual para o TA emergente (no trecho analisado anteriormente) foi assegurar que o TA aparecia corretamente na tela e que as soluções eram precisas o suficiente (como na mudança de "in Folge" para "nach" como tradução de "following") ou estavam suficientemente de acordo com a estrutura frasal na LA (como visto nas modificações empreendidas nas Figuras de 7 a 9). A Mudança 8 teve uma motivação diferente e mostrou como a atenção do tradutor mudou para a leitura e avaliação de uma 
solução que tinha sido digitada - mas não totalmente aceita - e estava, portanto, atrasando a produção.

É óbvio que, com os dados do olhar, podemos saber muito sobre onde está a atenção do tradutor quando nada está sendo digitado. Podemos fazer suposições muito mais robustas sobre os problemas de processamento específicos de que o tradutor se ocupou durante uma pausa na digitação. Entretanto, será que também podemos saber mais sobre a segmentação do texto feita pelo tradutor, sobre o escopo das unidades com que ele trabalha?

A análise de segmentos baseada em pausas e acionamentos de teclas resultou em somente três segmentos, pelo critério de no mínimo $1 \mathrm{~s}$, e em seis, pelo critério de pelo menos $0,9 \mathrm{~s}$. Três segmentos, portanto, foram limítrofes (com pausas entre 0,905 e 0,983 s) de acordo com o último critério. Uma redução adicional do critério de pausa para pelo menos $700 \mathrm{~ms}$ teria gerado mais quatro segmentos. Em dois desses casos, a pausa foi causada aparentemente por alguma atividade de edição do texto. Isso demonstra que a atenção pode ser rapidamente dirigida para microfenômenos relacionados com a digitação da representação do texto-alvo. Todavia, apesar de serem claramente refletidos nos dados de acionamentos de teclas e mouse, incidentes de representação no nível da superfície não ajudam a identificar em qual segmento ou conteúdo mais amplo estava o principal foco do tradutor em dado momento. Com base no critério de pelo menos $0,9 \mathrm{~s}$, a segmentação baseada em pausas e acionamentos de teclas resultou nos seguintes sete segmentos: /Gestern wurde / er / des vierfachen Morde /

in Folge eines la / 44 nach langem F Ver Gerichtsverfahren / des vierfachen Mordes schguldig gesprochen./. Em que medida essa segmentação tem correspondência com o que é indicado pelos dados do olhar? 
Tabela 1 - Unidades do TF lidas (linha 1) e unidades do TA lidas ou monitoradas (linha 2) durante visitas alternadas à Win1 e à Win2, com a atividade de digitação exibida na última linha

\begin{tabular}{|c|c|c|c|c|c|c|c|c|c|}
\hline $\begin{array}{l}\text { Win1: } \\
\text { Texto-fonte } \\
\text { lido (ou } \\
\text { relido) }\end{array}$ & $\begin{array}{l}\text { Yesterday, } \\
\text { he was } \\
\text { found } \\
\text { guilty of } \\
\text { four }\end{array}$ & $\begin{array}{l}\text { guilty } \\
\text { of four } \\
\text { counts } \\
\text { of } \\
\text { murder }\end{array}$ & \multicolumn{3}{|c|}{$\begin{array}{l}\text { counts of murder following } \\
\text { a long trial }\end{array}$} & following a long trial & $\begin{array}{l}\text { Yesterday, he } \\
\text { was found } \\
\text { guilty }\end{array}$ & $\begin{array}{l}\text { found guilty of } \\
\text { four counts of } \\
\text { murder he was } \\
\text { found guilty }\end{array}$ & $\begin{array}{l}\text { long trial. } \\
\text { He was } \\
\text { given four } \\
\text { life } \\
\text { sentences }\end{array}$ \\
\hline $\begin{array}{l}\text { Win2: } \\
\text { Texto-alvo } \\
\text { lido, relido } \\
\text { ou } \\
\text { monitorado } \\
\text { durante a } \\
\text { digitação }\end{array}$ & $\begin{array}{l}\text { Gestern॰w } \\
\text { urde• }\end{array}$ & $\begin{array}{l}\text { wurde } \\
\text { er• }\end{array}$ & \multicolumn{3}{|c|}{$\begin{array}{l}\text { wurde er des vierfachen } \\
\text { Morde } \\
\text { des vierfachen Morde } \\
\text { in Folge }\end{array}$} & $\begin{array}{l}\text { wurde er in Folge eines la } \\
\text { wurde er in Folge eines la } \\
\text { in Folge einesønach langem F } \\
\text { Ver Gerichtsverf }\end{array}$ & $\begin{array}{l}\text { verfahren des } \\
\text { vier }\end{array}$ & $\begin{array}{l}\text { schguldig } \\
\text { gespro• }\end{array}$ & \\
\hline $\begin{array}{l}\text { Texto-alvo } \\
\text { digitado } \\
\text { (segmentado } \\
\text { pelo critério } \\
\text { de } \\
\text { delimitação } \\
\text { de pausas de } \\
\text { pelo menos } \\
0.9 \mathrm{~s} \text { ) }\end{array}$ & \multicolumn{2}{|l|}{$\begin{array}{l}{[\bullet 01.529]} \\
\text { Gestern } \\
\bullet \text { wurde• } \\
{[\bullet 00.874] \text { er }}\end{array}$} & $\begin{array}{l}{[\bullet 00.944]} \\
\text { des } \\
\text { vierfachen } \\
\bullet \text { Morde }\end{array}$ & {$\left[\begin{array}{l}\cdot 01.5 \\
60] \\
4\end{array}\right.$} & {$\left[\begin{array}{l}\cdot 00.905] \\
\text { in } \bullet \text { Folge } \bullet \\
\text { eines } \bullet 1 \\
{[\bullet 00.608]} \\
\text { la }\end{array}\right.$} & $\begin{array}{l}{[\bullet 04.493] \text { nach } \bullet[\bullet 00.359]} \\
\text { lange }[\bullet 00.843] \mathrm{m} \cdot \mathrm{F}[\bullet 00.359] \\
{[\text { Shift+Back]Ver }[\bullet 00.375]} \\
{[\text { Shift }+ \text { Back }] \text { Gerichtsverfahren }} \\
\bullet\end{array}$ & \multicolumn{2}{|c|}{$\begin{array}{l}{[\bullet 00.983] \text { des } \bullet \text { vier }} \\
\text { fachen } \bullet \text { Mordes } \bullet[\bullet 00.765] \\
\text { schg } \bullet[\bullet 00.702]<u[\bullet 00.234] \text { ldig } \bullet \\
\text { Gesprochen. }\end{array}$} & \\
\hline $\begin{array}{l}\text { Glosa (erros } \\
\text { de digitação } \\
\text { foram } \\
\text { excluídos) }\end{array}$ & \multicolumn{2}{|c|}{ Ontem, foi ele } & $\begin{array}{l}\text { de } \text { quatro } \\
\text { acusações } \\
\text { de } \\
\text { homicídio }\end{array}$ & 4 & $\begin{array}{l}\text { após [1] } \\
\text { um lo }\end{array}$ & após [2] um longo julgamento & \multicolumn{2}{|c|}{$\begin{array}{l}\text { de quatro acusações de } \\
\text { homicídio culpado considerado. }\end{array}$} & \\
\hline
\end{tabular}

A grande vantagem de adicionar os dados do percurso do olhar aos dados de acionamentos de teclas e mouse é que se estabelece, entre o TF e o TA emergente, uma conexão comportamental explícita, em vez de uma conexão inferida. Ao olhar para a atividade realizada em cada mudança do percurso do olhar, pode-se estabelecer uma conexão explícita entre o que acabou de ser lido no TF e o que foi digitado mais ou menos simultaneamente ou depois de algum tempo. O primeiro trecho do TF que o tradutor leu lhe permitiu traduzir somente "Yesterday, he was" ("Gestern wurde er") porque, antes mesmo de digitar "er", ele já estava consciente de que precisaria ler mais material do TF para obter a ordem correta das informações na estrutura frasal alemã, percebendo que não seria possível (de acordo com as regras normativas de que dispunha para o alemão) continuar a sentença da seguinte forma: *"Gestern wurde er schuldig gesprochen des vier [??]" ou *"Gestern wurde er des vier [??] schuldig gesprochen". Portanto, fez-se necessária a Mudança 3 para a Win1. Enquanto percebia isso, o tradutor digitou "er", visivelmente em resposta ao que tinha sido lido após a Mudança 1. Logo, do ponto de vista da leitura, "er" não deveria ser tratado como um segmento separado, embora a pausa de digitação delimitada antes de "er" tenha durado perto de $0,9 \mathrm{~s}$.

A segunda sequência de leitura do TF foi improdutiva no sentido de que nenhum TA foi produzido em resposta ao que fora lido. O comportamento do olhar sugere uma etapa 
independente, porém sem correspondência com os dados de acionamentos de teclas. Essa etapa acrescentou material textual novo à memória do tradutor, mas, em um primeiro momento, ele não foi capaz de fazer uso desse material ou não estava seguro (ANGELONE, 2010, p. 18) sobre como usá-lo.

Somente após olhar pela segunda vez para "counts of murder", na terceira sequência de leitura do TF, é que o tradutor se convenceu de que era possível continuar a tradução. Então, digitou a tradução de "of four counts of murder", sabendo que agora era possível construir o TA de forma correta e apropriada como "Gestern wurde er des vierfachen Mordes schuldig gesprochen".

A representação do processo de leitura na primeira linha da Tabela 1 infelizmente não tem um eixo temporal adequado e, por conseguinte, não mostra claramente como a leitura influenciou o processo decisório, o que está refletido mais claramente nos dados dos acionamentos de teclas na terceira linha. Porém, o indício para se entender a decisão por excluir "des vierfachen Morde" está nos dados do olhar. A descoberta inesperada, logo após a digitação de "des vier", de uma unidade de texto ("following a long trial") que não fazia parte do padrão até então previsto para sentença-alvo e que não poderia simplesmente ser incluso de forma linear no texto-alvo já existente, forçou o tradutor a produzir um novo padrão de texto-alvo que integraria a nova unidade. A nova e inesperada unidade traduzível estava, obviamente, no centro da atenção, mas forçou o tradutor a estender a atenção para a construção completa da sentença e repensá-la. Esse processo demonstra como uma nova unidade de atenção pode, repentinamente, forçar o tradutor a remodelar uma unidade de atenção maior para que possa acomodar a unidade menor. A combinação de dados do olhar e de acionamentos de teclas e mouse permite-nos perceber que os segmentos entendidos como unidades cognitivas não são meras partes de uma sequência de letras; estão mais para células orgânicas que podem combinar-se em múltiplas dimensões.

Depois de decidir reestruturar a ordem dos sintagmas para que a tradução de "following a long trial" viesse imediatamente após "Gestern wurde er", o tradutor excluiu "des vierfachen Morde", deixando livre um espaço suficiente para a continuação da sentença com "in Folge". Isso levou à produção da seguinte estrutura da sentença em alemão: "Gestern wurde er / in Folge eines langen Gerichtsverfahren / des vierfachen Mordes schuldig gesprochen". Porém, a digitação parou depois de "la", na palavra "langen", devido a um novo problema referente à interpretação da relação sinalizada por "following": será que "following" sugere que a decisão do tribunal foi um resultado ou ("in Folge") do julgamento? Ou será que 
simplesmente sugere que a decisão foi anunciada após ("nach") o julgamento? Depois de um período de reflexão de mais ou menos $4,5 \mathrm{~s}$, a primeira sugestão do tradutor ("in Folge") finalmente deu lugar à interpretação temporal (“nach").

Nesse caso, mais uma vez, os dados do olhar foram cruciais, dando informações sobre o escopo da unidade de atenção. O problema se centrava, evidentemente, em torno da adequação de "in Folge", que acabou sendo substituído por "nach", mas os dados do olhar mostram que o tradutor estava lendo e revisando uma unidade maior, "wurde er in Folge eines la(ngen Gerichtsverfahren)", que foi lida repetidamente durante mais de 4 s. A unidade de atenção, novamente, era uma unidade dentro de outra unidade: havia um lócus de atenção focada, mas a atenção estava muito mais em como essa unidade se encaixava em uma área maior de atenção.

O relato ora apresentado sugere uma nova forma de identificar unidades de tradução com base na busca visual e cognitiva do tradutor por unidades traduzíveis e no seu eventual intento em integrar unidades novas a uma unidade maior de toda a sentença ou texto. $\mathrm{Na}$ sentença aqui analisada, havia três unidades dessa natureza: (1) "Yesterday, he was found guilty" (2) "of four counts of murder" (3) "following a long trial". O desafio de reestruturar a sentença se encontrava em partir da ordem das palavras no original para: "Yesterday, was he / following a long trial / of four counts of murder / guilty found". Em outras palavras, cabia ao tradutor inverter "he was" para "was he", deixar "found guilty" para o final, mover todo o conteúdo de (3) para antes de (2) e, por fim, inverter "found guilty" para "guilty found". Para o tradutor experiente em questão, o desafio estrutural foi tão ínfimo que ele pôde priorizar a tradução por unidade traduzível e apenas ler adiante na sentença o necessário para capturar essa unidade. As mudanças estruturais e transições entre elementos estruturais foram responsáveis por quatro das cinco pausas (à exceção da pausa inicial) com duração maior que $0,9 \mathrm{~s}$, totalizando $4,4 \mathrm{~s}$, o equivalente a mais ou menos a duração da pausa longa antes de "nach", que acabou sendo o único desafio de grande esforço. Após decidir usar "nach", o tradutor desenvolveu o restante da tarefa com facilidade, fazendo somente três visitas curtas ao texto-fonte.

A Tabela 1 mostra que, no geral, há boa correspondência entre as unidades baseadas nas mudanças do percurso do olhar e as unidades baseadas nos intervalores maiores que $0,9 \mathrm{~s}$ entre os acionamentos de teclas. Desconsiderando a mudança final (Mudança 13), em que o percurso do olhar passou para a sentença seguinte àquela ora analisada (depois de ancorada a leitura em "long trial"), houve seis pares de mudanças no percurso do olhar (TF $\rightarrow \mathrm{TA})$ e seis 
segmentos definidos com base nas pausas e acionamentos de teclas. Eles não necessariamente são correspondentes - em parte, por conta das habilidades de digitação do tradutor, que conseguia ler material novo do TF antes de terminar de digitar a tradução de um trecho do TF lido anteriormente. A principal vantagem de identificar unidades de processamento com base nas mudanças do percurso do olhar da leitura do TF para o monitoramento ou a leitura do TA é que os processos de compreensão e de produção são reunidos em uma bela narrativa dialógica contendo perguntas e respostas.

\section{Agradecimentos}

O autor agradece ao editor e a um revisor anônimo pelas inúmeras e úteis sugestões feitas para a produção da versão final deste texto.

\section{Referências}

ALVES, F.; VALE D. Probing the unit of translation in time: aspects of the design and development of a web application for storing, annotating, and querying translation process data. Across Languages and Cultures, v. 10, n. 2. p. 251-273, 2009.

ANGELONE, E. Uncertainty, uncertainty management and metacognitive problem solving in the translation task. In: SHREVE, G.; ANGELONE, E. (Ed.). Translation and cognition. Amsterdã: John Benjamins, 2010. p. 17-40.

BADDELEY, A. D. Working memory. Oxford: Clarendon Press, 1986.s'sep:

BALLING, L. W.; HVELPLUND, K. T.; SJØRUP, A. C. Evidence of parallel processing during translation. Meta, v. 59, n. 2, p. 234-259, 2014

BUTTERWORTH, B. Evidence from pauses in speech. In: BUTTERWORTH, B. (Ed.). Language production: speech and talk. Londres: Academic Press, 1980. p. 155-176

CARL, M.; KAY, M. Gazing and typing activities during translation: a comparative study of translation units of professional and student translators. Meta, v. 56, n. 4, p. 952-975, 2011.

CARL, M.; DRAGSTED, B. Inside the monitor model: processes of default and challenged translation production. Translation: Corpora, Computation, Cognition, v. 2, n. 1. p. 127-145, 2012.

CHESTERMAN, A. Readings in translation theory. Helsinki: Finn Lectura, 1989.

DE GROOT, A. M. B. The cognitive study of translation and interpretation. In: DANKS, J. H.; SHREVE, G. M.; FOUNTAIN, S. B.; MCBEATH, M. K. (Ed.). Cognitive processes in translation and interpreting. Londres: Sage Publications, 1997. p. 25-56.

DRAGSTED, B. Segmentation in translation and translation memory systems. an empirical 
investigation of cognitive segmentation and effects of integrating a TM system into the translation process. 369 f. 2004. Tese (Doutorado) - Copenhagen Business School, Copenhagen, 2004.

DRAGSTED, B. Segmentation in translation: differences across levels of expertise and difficulty. Target, v. 17, n. 1, p. 49-70, 2005.

DRAGSTED, B. Coordination of reading and writing processes in translation: An eye on uncharted territory. In: SHREVE, G.; ANGELONE, E. (Ed.). Translation and cognition. Amsterdã: John Benjamins, 2010. p. 41-62.

DRAGSTED, B. I.; HANSEN, G. Comprehension and production in translation: a pilot study on segmentation and the coordination of reading and writing processes. Copenhagen Studies in Language, v. 36, p. 9-29, 2008.

GOLDMAN-EISLER, F. Pauses, clauses, sentences. Language and Speech, v. 15, n. 2, p.

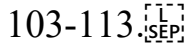

IMMONEN, S.; MÄKISALO, J. Pauses reflecting the processing of syntactic units in monolingual text production and translation. Hermes - Journal of Language and Communication Studies, v. 44, p. 45-61, 2010.

IVIR, V. Formal correspondence vs. translation equivalence revisited. Poetics Today v. $2, \mathrm{n}$. 4, p. 51-59, 1981.

JAKOBSEN, A. L. Effects of think aloud on translation speed, revision, and segmentation. In: ALVES, F. (Ed.). Triangulating translation: perspectives in process oriented research. Amsterdã: John Benjamins, 2003. p. 69-95.

SCHILPEROORD, J. It's about time: temporal aspects of cognitive processes in text production. Amsterdã: Rodopi, 1996.

TIMAROVÁ, S.; DRAGSTED, B.; GORM HANSEN, I. Time lag in translation and interpreting. In: ALVSTAD, C.; HILD, A.; TISELIUS, E. (Ed.). Methods and strategies of process research: integrative approaches in Translation Studies. Amsterdã: John Benjamins, 2011. p. 121-146.

TIRKKONEN-CONDIR, S. The monitor model revisited: evidence from process research. Meta, v. 50, n. 2. p. 405-414, 2005. 
